\title{
Density Functional Theory Study of Intermolecular Interactions between Amylum and Cellulose
}

\author{
Raynardthan Pontoh ${ }^{1}$, Vania Edita Rarisavitri ${ }^{1}$, Christine Charen Yang ${ }^{1}$, Maximilliam Febriand Putra ${ }^{2}$, \\ and Daru Seto Bagus Anugrah ${ }^{{ }^{*}}$
}

${ }^{1}$ Undergraduate Program, Biotechnology Study Program, Faculty of Biotechnology, Atma Jaya Catholic University of Indonesia, BSD Campus, Tangerang 15345, Indonesia

${ }^{2}$ Undergraduate Program, Food Technology Study Program, Faculty of Biotechnology, Atma Jaya Catholic University of Indonesia, BSD Campus, Tangerang 15345, Indonesia

\section{*Corresponding author:}

email:daru.seto@atmajaya.ac.id

Received: September 19, 2021

Accepted: December 13, 2021

DOI: $10.22146 / \mathrm{ijc} .69241$

\begin{abstract}
Amylum is one of the polysaccharides developed into biodegradable plastic bags. However, amylum-based plastics are easily damaged due to their low mechanical strength and hydrophilic properties. Cellulose is used as a support material in amylumbased plastics to increase strength and reduce water damage. This study investigated the molecular interactions between amylum and cellulose computationally. The minimum interaction energy of amylum and cellulose was calculated using in silico modeling using the Density Functional Theory (DFT) method. The B3LYP function and the basis set 6$31++g^{* *}$ were used in the calculations. Simultaneously, D3 Grimme dispersion correction was used as the effect of water solvent in the measures. The results obtained from this study were the interaction energy of amylum and cellulose of $-29.8 \mathrm{kcal} / \mathrm{mol}$. The HOMO-LUMO energy gap of the cellulose-amylum complex was lower than cellulose, indicating that the cellulose-amylum complex was more reactive and bonded to each other. Analysis of Natural Bond Orbital (NBO), Quantum Theory Atom in Molecule (QTAIM), Reduced Density Gradient (RDG), Non-covalent Interaction Index (NCI), and Intrinsic Bond Strength Index (IBSI) showed that the cellulose-amylum complex had weak to medium intermolecular bonds. The hydrogen bond at O61‥H48 was the strongest in the complex. All data show that cellulose and amylum could interact through non-covalent bonds.
\end{abstract}

Keywords: amylum; DFT; cellulose; computational chemistry; intermolecular bonds

\section{- INTRODUCTION}

Cellulose and amylum are polysaccharides abundant in nature and often found in plant cell walls, including coconut fiber. Cellulose has a long linear chain structure consisting of D-glucose units with beta-1,4 glycoside bonds [1-2]. Generally, cellulose is rigid, insoluble in water, and strong. Cellulose is insoluble in water due to the intra- and intermolecular hydrogen bonds between the hydroxyl groups in the cellulose chain [3]. Amylum consists of two kinds of polysaccharide mixture, namely amylose and amylopectin. Amylose is an amylum component with a straight chain, consisting of glucose units with alpha- $(1,4)$-D-glucose bonds, and is soluble in water.

Meanwhile, amylopectin is an amylum component with a branched-chain, consisting of glucose units with 1,4-D-glucose and 1,6-D-glucose bonds. Due to the amylum's nature, which is easily soluble in hot water, amylum has been widely developed into bioplastics. However, low mechanical strength is a limitation of amylum-based bioplastics so that they are easily damaged. Mixing between amylum and cellulose improved the mechanical properties of amylum-based bioplastics by forming hydrogen bonding, which resulted in the improved mechanical properties of bioplastics [4]. Other

Raynardthan Pontoh et al. 
interactions, such as Van der Waals (VdW) interactions, also play a role in the interactions of the polymers matrix. VdW interactions can be found between polymer repeating units and are significant forces between the side chains with repulsive, attractive dipole effects [5-7].

Theoretically, research can be done using in-silico modeling, explicitly identifying the interactions between molecules. The computational analysis method is a systematic calculation using computer equipment that has been widely used to determine the properties of atoms or molecules [8-9]. One computational method that uses a quantum mechanical approach is Density Functional Theory (DFT). DFT calculations can measure atoms or molecules' properties and structural properties based on electron density [10]. The DFT method was previously used in comprehensive research to study minor to large molecules [11-13]. However, due to its limitations, DFT studies on polymers usually use dimer structures [11,14]. Moreover, dimer structures can represent interactions with larger structures such as trimers and oligomers because their structure is not significantly different [15].

DFT has also been used in evaluating the structure of cellulose dimers [16] and amylum [17]. So far, there has been no reported research on the interaction of cellulose-amylum complex using the DFT method [18]. Therefore, this study aims to evaluate the celluloseamylum complex's molecular interactions deeply. The dimer structures of cellulose and amylum were used to represent the cellulose and amylum polymers, respectively. The optimum molecular structure, interaction energy, and type of bond were analyzed in this study. The results of this computational research can be used as reference material for developing amylumcellulose-based bioplastics in the future.

\section{- COMPUTATIONAL METHODS}

\section{Computational Details}

The software used for computational modeling is NWChem, Multiwfn, and NBO 7.0. The effect of water was added to the calculation process using the Grimme D3 dispersion correction [19]. All data were calculated on NWChem [20]. The data were processed using
Multiwfn to obtain the properties of the estimated molecules [1,21-22]. NBO 7.0 was used to analyze the probability of interaction between non-Lewis's acceptors and compute their respective energies $[1,21,23]$. The hardware was a server computer at CV Efison Lisan Teknologi and the Biochemistry and Enzyme Technology Laboratory, the Faculty of Biotechnology, Atma Jaya Catholic University of Indonesia.

\section{Interaction Energy}

The calculations in this study used the dimer structure of cellulose and amylum molecules. The 3D dimer structures of amylum and cellulose molecules were downloaded first with codes 439341 and 14055602 from PubChem, respectively. The structures with minimum energy were obtained through individual optimization using NWChem software with DFT method on the basis set $6-31++\mathrm{g}^{* *}$ and Becke's functional three-parameter functional (B3LYP). The energy optimization of various position cellulose-amylum complexes is presented in Fig. S1. Position 1 was used to explain the interaction of the cellulose-amylum complex due to the lowest of energy optimization. The effect of the solvent was added to the calculation process using the Grimme D3 dispersion correction. After the optimized structure, the cellulose, amylum, and cellulose-amylum complex frequency were calculated. Then, the Basis Set Super-Position Error (BSSE) and zero-point correction to energy (ZPE) were calculated to determine the interaction energy with the full counterpoise method [12,24]. The interaction energy $\left(\mathrm{E}_{\text {int }}\right)$ of amylum-cellulose was obtained according to Eq. (1) [25].

$$
\begin{aligned}
\mathrm{E}_{\text {int }}= & \mathrm{E}_{\text {Amylum-celluose }}-\left(\mathrm{E}_{\text {Amylum }}+\mathrm{E}_{\text {cellulose }}\right) \\
& +\mathrm{E}_{\text {BSSE Amylum-cellulose }}
\end{aligned}
$$

\section{Complex Reactivity Analysis}

The energy of the Highest Occupied Molecular Orbital-Lowest Unoccupied Molecular Orbital (HOMOLUMO) was obtained from the calculation results in NWChem. HOMO energy was formed when a molecule released electrons or ionization energy (I), while LUMO energy is a molecular process of accepting electrons or affinity energy (A). The chemical parameters used 
consisted of electron affinity (A) and electronegativity $(X)$ and were calculated using Eq. (2) and (3), respectively. In addition, the HOMO-LUMO energy gap $(\Delta \mathrm{E})$ was also taken into account to determine the ability of each complex to transfer electrons using Eq. (4) [26].

$$
\begin{aligned}
& \mathrm{A}=-\mathrm{E}_{\text {LUMO }} \\
& \chi=-\frac{1}{2}\left(\mathrm{E}_{\mathrm{HOMO}}+\mathrm{E}_{\mathrm{LUMO}}\right) \\
& \Delta \mathrm{E}=\mathrm{E}_{\mathrm{LUMO}}-\mathrm{E}_{\text {HOMO }}
\end{aligned}
$$

\section{Natural Bond Orbital (NBO) Analysis}

In this study, NBO 7.0 software would be used to analyze the molecular interactions in amylum and cellulose to obtain the value of stabilization energy [8]. Natural Bond Orbital (NBO) analysis also evaluates intra- and intermolecular interactions in the form of a charge distribution, the reactivity for proton transport, and the type of bond energy. The stabilization energy $\mathrm{E}^{(2)}$ between the electron donor and the acceptor was obtained from Eq. (5) [27].

$\mathrm{E}^{(2)}=\Delta \mathrm{E}_{\mathrm{ij}}=\frac{\mathrm{q}_{\mathrm{i}} \mathrm{F}_{\mathrm{ij}}^{2}}{\varepsilon_{\mathrm{j}}-\varepsilon_{\mathrm{i}}}$

where $q_{i}$ is the donor orbital occupancy, $\varepsilon_{j}$ and $\varepsilon_{i}$ are diagonal elements, and $F_{i j}$ is the diagonal NBO Fock matrix element.

\section{Quantum Theory Atom in Molecule (QTAIM) Analysis}

QTAIM analysis was carried out to calculate and study the hydrogen bonding interaction at Binding Critical Point (BCP). The analysis was performed by Multiwfn 3.8 program. The QTAIM computation was obtained using the topological parameters, such as density $(\rho(\mathrm{BCP}))$, Laplacian of the charge density $\left(\nabla_{2} \rho\right)$, ellipticity index $(\varepsilon)$, components of Laplacian in $x, y, z\left(\lambda_{1}\right.$, $\lambda_{2}, \lambda_{3}$ ), electronic energy density $H_{B C P}$, kinetic energy density $\mathrm{G}_{\mathrm{BCP}}$, potential energy density $\mathrm{V}_{\mathrm{BCP}}$, and $\mathrm{H}$-bond binding energy $\mathrm{E}_{\mathrm{HB}}$ [28]. The density value in the Laplacian concept was obtained by the formula $\mathrm{H}_{\mathrm{BCP}}=$ $\mathrm{G}_{\mathrm{BCP}}+\mathrm{V}_{\mathrm{BCP}}$ and was expressed as $\lambda_{1}, \lambda_{2}$, and $\lambda_{3}$ [29]. There was also a density value on kinetic energy symbolized by $G_{B C P}$ and $V_{B C P}$, which showed potential energy density in the interactions. A weak covalent interaction with a strong electrostatic bond is indicated by $\nabla_{2} \rho(+)$ and $\mathrm{H}_{\mathrm{BCP}}$ $(+)$. Meantime $\nabla_{2} \rho(-)$ and $\mathrm{H}_{\mathrm{BCP}}(-)$ show a strong covalent bond with strong covalent interaction. For the time being, a medium strength indicated by $\nabla_{2} \rho(+)$ and $\mathrm{H}_{\mathrm{BCP}}(-)$ has a partially covalent bond. The value of $\mathrm{V} / \mathrm{G}$ was used as a parameter in an interaction that occurs, with a value less than 1 interpreting a weak interaction, a value between 1 and 2 interpreting a medium interaction, and a value above 2 interpreting a substantial interaction value [30-31].

\section{Reduced Density Gradient (RDG) and Non-covalent Index (NCl)}

Amylum and cellulose have intramolecular interactions that can be seen by using the Reduced Density Gradient (RDG) and Non-covalent index (NCI) graph [32]. In addition, NCI could provide information about the type of bond present in the molecule. The RDG and NCI index graphs can be achieved using the Multiwfn application. RDG is calculated by Eq. (6) [17].

$$
\mathrm{RDG}=\frac{1}{2\left(3 \pi^{2}\right)^{1 / 3}} \frac{|\nabla \rho(\mathrm{r})|}{\rho(\mathrm{r})^{4 / 3}}
$$

The sign $\lambda_{2} \rho$ and RDG scale were plotted for the RDG graph. Values $\lambda_{2} \rho$ and provide information about the intramolecular bonding of amylum and cellulose molecules. A strong bond, including hydrogen bonds, is achieved when the value of $\lambda_{2} \rho$ is $<0$ and $\rho$ is $>0$. Van der Walls interaction has resulted when the value of $\lambda_{2} \rho$ and $\rho$ is around 0 or 0 . The steric effect, which is a repulsive effect, is gained when the value $\lambda_{2} \rho$ is $>0$ and $\rho$ is $<0$ [30].

\section{Intrinsic Bond Strength Index (IBSI)}

Analysis of the strength of the existing atomic pairs and intramolecular interactions both covalently and non-covalently can be measured by the value of chemical bonds using the IBSI value approach based on its intrinsic strength [32]. The IBSI value is a value that can assess the intermolecular chemical bond strength of a molecule. This IBSI value is related to the bond-strain force constant but is not affected by the curvature of the transition states or the ring's boundary. The IBSI value is derived from the IGM $\partial \mathrm{g}^{\text {pair }}$ obtained for a particular atomic pair. In addition, IBSI can quantify the counter gradience in the region between 2 atoms having different 
properties and consider only the orbital contribution of the two atoms. IBSI is also identified using parameterfree and straightforward implementation, requiring only wave function as input data, to analyze the data intermolecularly [30]. IBSI is calculated by Eq. (7) [30].

$$
\Delta \mathrm{g}^{\text {pair }}=\frac{\int \mathrm{v} \frac{\delta \mathrm{g}^{\text {pair }}}{\mathrm{d}^{2}} \mathrm{dV}}{\int \mathrm{v} \frac{\delta \mathrm{g}^{\mathrm{H} 2}}{\mathrm{~d}^{2} \mathrm{H} 2} \mathrm{dV}}
$$

\section{- RESULTS AND DISCUSSION}

\section{Interaction Energy}

The 3D structure obtained from the PubChem website was optimized using the NWChem software using the B3LYP DFT-D3/6-31++g** level theory $[18,33]$. This computational research used a dimer structure because dimers have almost a similar enthalpy and interaction energy to trimers and oligomers [8]. However, using many atoms would increase the calculation time and increase the costs required during the calculation process.

The optimization results of the cellulose-amylum complex are shown in Fig. 1. The position of the cellulose-amylum complex was the lowest optimization energy compared to other positions (Fig. S1). The position was chosen to explain the cellulose-amylum interactions. The optimized structure presented a

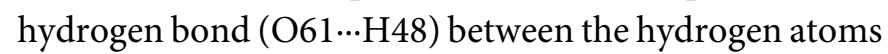
in cellulose and the carbonyl group $(\mathrm{C}=\mathrm{O})$ in amylum with a distance of $1.842 \AA$. In addition, there was a hydrogen bond at $\mathrm{O} 2 \cdots \mathrm{H} 95$, which is slightly further away ( $\mathrm{r} \mathrm{OH}=1.999 \AA)$. The interaction energy in the complex was $-29.8 \mathrm{kcal} / \mathrm{mol}$, which indicated a strong hydrogen bond interaction [11].

\section{Molecular Reactivity Analysis}

The HOMO-LUMO analysis showed several parameters of chemical properties, including electron affinity (A), ionization energy (I), and electronegativity $(\chi)$ to describe the level of reactivity in a molecule. The $\Delta \mathrm{E}$ is used to determine and analyze the ability of each compound to transfer electrons. If the energy gap gets smaller, the compound will be easier to transfer electrons.

The $\Delta \mathrm{E}$ results are presented in Table 2 . The larger the value of the $\Delta \mathrm{E}$, the more rigid and stable the molecule.

Table 1. The interaction energy of cellulose-amylum complex

\begin{tabular}{llcl}
\hline Complex & Theoretical level & $\begin{array}{c}\text { Energy interaction } \\
(\mathrm{kcal} / \mathrm{mol})\end{array}$ & Hydrogen bond \\
\hline Cellulose-amylum & B3LYP & -29.8 & $\begin{array}{l}\mathrm{r}(\mathrm{O} 61 \cdots \mathrm{H} 48)=1.842 \AA \\
\mathrm{r}(\mathrm{O} 2 \cdots \mathrm{H} 95)=1.999 \AA\end{array}$ \\
& DFT-D3/6-31++g* & & \\
\hline
\end{tabular}

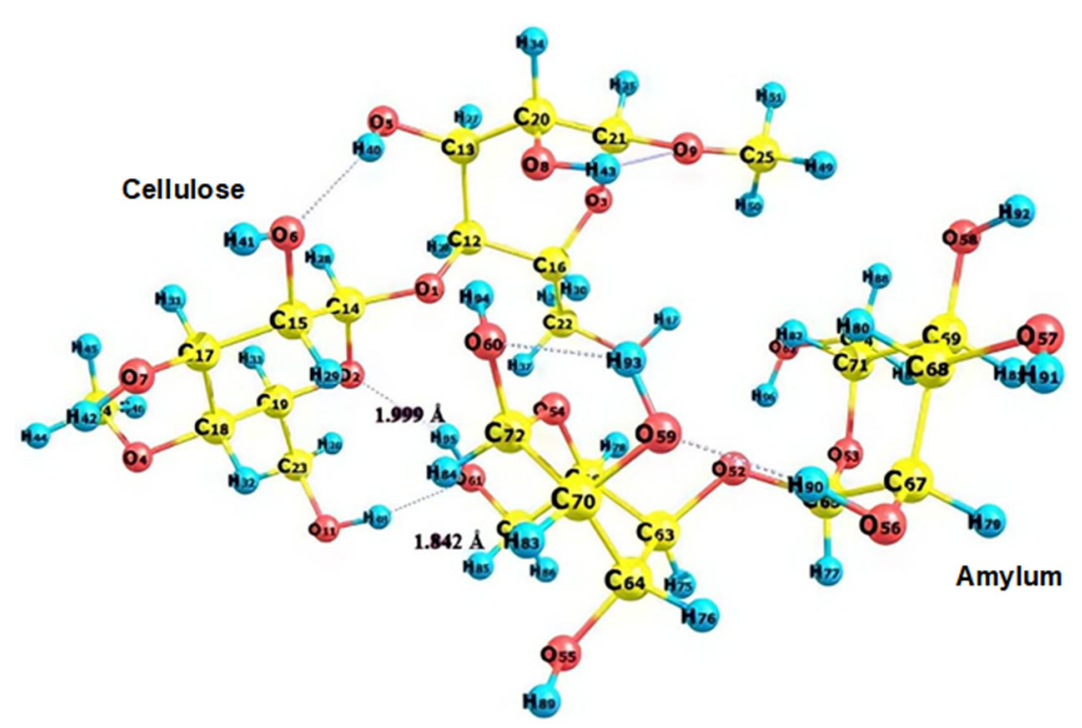

Fig 1. Optimized structure of the cellulose-amylum complex 
Table 2. Parameters of chemical properties of cellulose, amylum, and cellulose-amylum

\begin{tabular}{lccccc}
\hline Molecule & $\begin{array}{c}\mathrm{E}_{\text {Hомо }} \\
(\mathrm{eV})\end{array}$ & $\begin{array}{c}\mathrm{E}_{\mathrm{LUmo}} \\
(\mathrm{eV})\end{array}$ & $\begin{array}{c}\Delta \mathrm{E} \\
(\mathrm{eV})\end{array}$ & $\begin{array}{c}\mathrm{A} \\
(\mathrm{eV})\end{array}$ & $\begin{array}{c}\mathrm{X} \\
(\mathrm{eV})\end{array}$ \\
\hline Cellulose & -6.53 & 1.62 & 8.15 & -1.62 & -2.46 \\
Cellulose- & -6.76 & 1.15 & 7.91 & -1.15 & -2.81 \\
Amylum & & & & & \\
Amylum & -6.87 & 1.02 & 7.89 & -1.02 & -2.93 \\
\hline
\end{tabular}

Conversely, if the value of the gap between HOMO and LUMO was getting smaller, the molecule was more likely to donate electrons and was more reactive and therefore unstable [1]. In addition, higher electronegativity values would be more electrophilic. In Table 2, it could be seen that the $\Delta \mathrm{E}_{\text {cellulose-amylum }}(7.92 \mathrm{eV})$ was lower than cellulose with a value of $\Delta \mathrm{E}_{\text {cellulose }}(8.15 \mathrm{eV})$. It indicated that the complex was more accessible to transfer electrons than cellulose structure. This phenomenon supports the presence of cellulose in the matrix to strengthen the mechanical strength of amylum-based plastics [17].

The calculation results were also supported by the affinity (A) and electronegativity ( $\chi$ ) values. The cellulose-amylum $(-1.15 \mathrm{eV})$ was more positive than $\mathrm{A}_{\text {cellulose }}(-1.62 \mathrm{eV})$. From the affinity data, it could be concluded that cellulose-amylum forms a stronger bond than cellulose. In addition, the electronegativity value of the cellulose-amylum complex $(-2.81 \mathrm{eV})$ was lower than that of cellulose $(-2.46 \mathrm{eV})$. The affinity data indicates that amylum had a higher electronegativity value than cellulose, with electrophilic properties.

\section{Reduced Density Gradient (RDG) and NCI Index}

RDG and Non-covalent interaction index (NCI) were used to determine the intermolecular and weak interactions occurring naturally in amylum and cellulose. Complex interactions were determined by $\mathrm{RDG}$, and hydrogen interactions that function as non-covalent interactions were determined using NCI. Multiwfn program can be used to determine the value of $\left(\lambda_{2}\right) \rho(r)$, RDG-NCI plots, and graphs whose interactions can be seen from the values of $\lambda_{2}$ and $\rho$. Values of $\lambda_{2} \rho<0$ and $\rho$ $>0$ indicate strong bonds, such as hydrogen bonds and halogen bonds, symbolized by the blue area (Fig. 2 and 3). Meanwhile, the Van der Walls interaction (green area) is indicated by the value $\lambda_{2} \rho \approx 0$ and $\rho \approx 0$, and the steric effect (red zone) is indicated by the value $\lambda_{2} \rho>0$ and $\rho>0$.

Fig. 2 shows the interaction between amylum and cellulose. When cellulose-amylum was compared with amylum, the interaction had more hydrogen bonds. Likewise, if cellulose-amylum was compared to cellulose, the cellulose-amylum interaction had more hydrogen bonds. The blue bonds indicated this formed more frequently. In addition, the Van der Waals bonds in amylum and cellulose were quite a lot. When they interacted together, the Van der Waals bonds in celluloseamylum became more numerous. In addition, amylum and cellulose had a small amount of steric effect (Fig. 2).

The RDG graph in Fig. 3(a) showed that amylum and cellulose had stronger hydrogen bonds. Fig. 3(a)

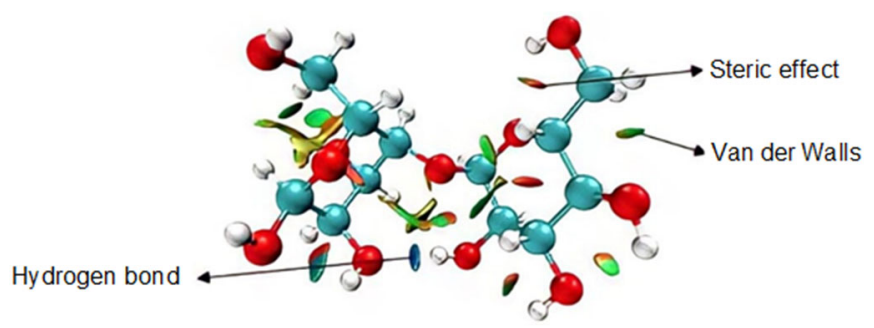

(a)

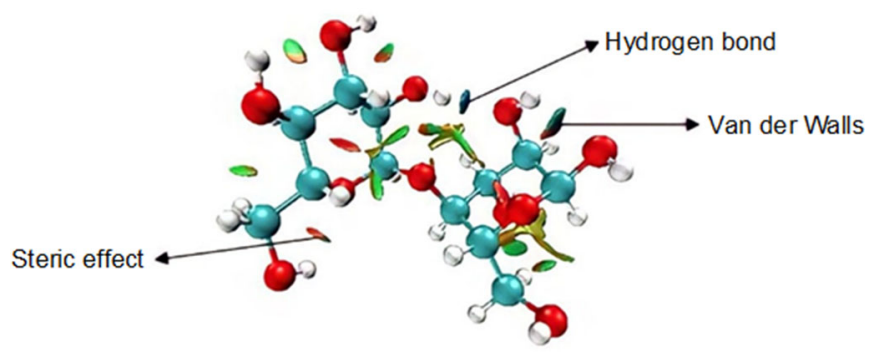

(b)

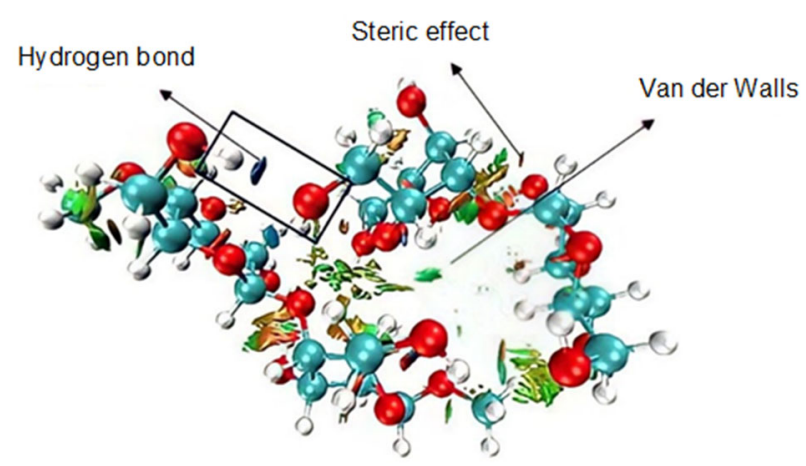

(c)

Fig 2. RDG isosurface (a) amylum, (b) cellulose, (c) cellulose-amylum 


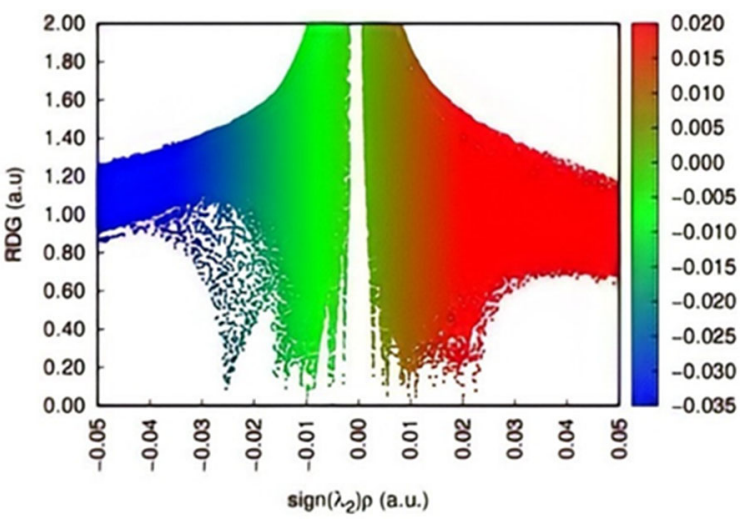

(a)

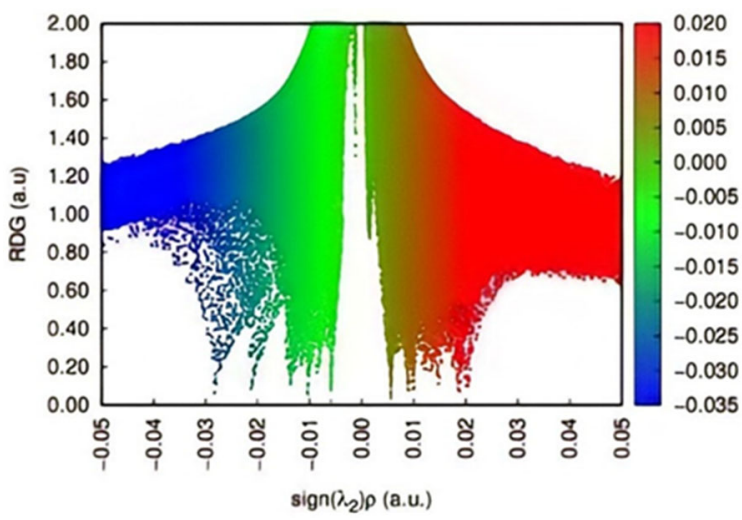

(b)

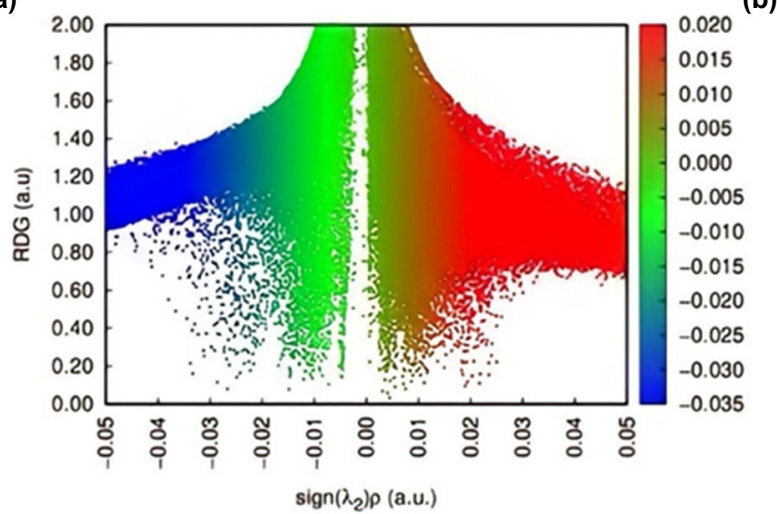

(c)

H-bond VdW interactions Steric effect

Fig 3. Scatter plots: (a) amylum, (b) cellulose, (c) cellulose-amylum complex

showed an interaction with amylum, while Fig. 3(b) displayed interactions with cellulose. The blue area indicated hydrogen bonds, the green area indicated van der Waals interactions, and the red area indicated steric effects. The interactions with amylum showed weak hydrogen bonds and interactions with cellulose. The strong hydrogen bond in the interaction of amylum and cellulose is indicated by blue dots that are more spread towards the value of $\left(\lambda_{2}\right)$ on the left or more negative so that the attractive interaction is more robust.

\section{Quantum Theory Atom in Molecule (QTAIM)}

QTAIM analysis was performed to study the interactions of the cellulose-amylum complex. The optimized complex structure data was processed using Multiwfn to generate topological parameter data $\left(\nabla_{2} \rho, G\right.$, $\mathrm{H}, \mathrm{V}$, and ratio $|\mathrm{V} / \mathrm{G}|$ ) [28-29] (Table S1). Based on QTAIM results, there were $15 \mathrm{BCP}$ in the celluloseamylum complex. The complex exhibited weak to medium non-covalent bonds. $\mathrm{E}_{\mathrm{HB}}$ values were in the range of -0.324 to $-6.791 \mathrm{kcal} / \mathrm{mol}$. The value of $\mathrm{E}_{\mathrm{Hв}}$ at BCP 120 and 125 showed higher energy than other bonds (Fig. 4). The value of $\nabla^{2} \rho$ was positive, $\mathrm{H}_{\mathrm{BCP}}$ was negative, and $1<|\mathrm{V} / \mathrm{G}|<2$ indicated intermediate binding strength at BCP $120(\mathrm{O} 61 \cdots \mathrm{H} 48)$ and $125(\mathrm{H} 95 \cdots \mathrm{O} 2)$.

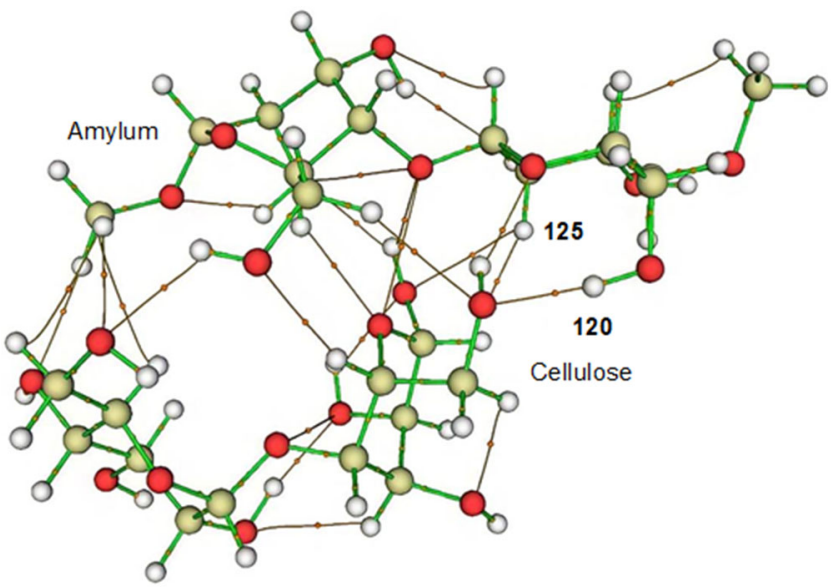

Fig 4. BCP index of the cellulose-amylum complex 
Table 3. Results of the natural bond orbital analysis on cellulose-amylum complex

\begin{tabular}{|c|c|c|c|}
\hline Donor (i) & Acceptor (j) & $\mathrm{E}^{(2)}(\mathrm{Kcal} / \mathrm{mol})$ & Distance, $r(\AA)$ \\
\hline \multicolumn{4}{|c|}{ Cellulose-Amylum } \\
\hline $\mathrm{Lp}(1) \mathrm{O} 1$ & $\mathrm{BD}^{\star}(1) \mathrm{O} 60-\mathrm{H} 94$ & 3.75 & 2.218 \\
\hline $\mathrm{Lp}(1) \mathrm{O} 2$ & $\mathrm{BD}^{*}(1) \mathrm{O} 61-\mathrm{H} 95$ & 4.97 & 1.999 \\
\hline $\operatorname{Lp}(2) \mathrm{O} 8$ & $\mathrm{BD}^{\star}(1) \mathrm{O} 60-\mathrm{H} 94$ & 3.38 & 2.140 \\
\hline \multicolumn{4}{|c|}{ Amylum-Cellulose } \\
\hline $\mathrm{Lp}(1) \mathrm{O} 54$ & $\mathrm{BD}^{\star}(1) \mathrm{C} 16-\mathrm{H} 30$ & 2.80 & 2.266 \\
\hline Lp (2) O58 & $\mathrm{BD}^{*}(1) \mathrm{C} 25-\mathrm{H} 49$ & 3.27 & 2.255 \\
\hline $\operatorname{Lp}(2) \mathrm{O} 61$ & $\mathrm{BD}^{*}(1) \mathrm{O} 11-\mathrm{H} 48$ & 15.64 & 1.842 \\
\hline
\end{tabular}

Table 4. The results of the IBSI on the cellulose-amylum complex

\begin{tabular}{lccccc}
\hline Amylum & Cellulose & Distance $(\AA)$ & $\int \partial \mathrm{g}^{\text {pair }}$ & IBSI $^{\text {IGHM }}$ & IBSI $^{\text {IGM }}$ \\
\hline $61(\mathrm{O})$ & $48(\mathrm{H})$ & 1.842 & 0.060 & 0.036 & 0.167 \\
$2(\mathrm{O})$ & $95(\mathrm{H})$ & 1.999 & 0.056 & 0.028 & 0.104 \\
$6(\mathrm{O})$ & $40(\mathrm{H})$ & 1.987 & 0.048 & 0.024 & 0.108 \\
$59(\mathrm{O})$ & $90(\mathrm{H})$ & 1.881 & 0.061 & 0.034 & 0.149 \\
$60(\mathrm{O})$ & $93(\mathrm{H})$ & 1.992 & 0.048 & 0.024 & 0.116 \\
\hline
\end{tabular}

\section{Natural Bond Orbital (NBO) Analysis}

NBO analysis was carried out to identify the bonds in the cellulose-amylum complex. Electron delocalization of the electron pair (Lp) to an unoccupied anti-bonding orbital $\left(\mathrm{BD}^{\star}\right)$ occurred in the interacting atoms (Table 3). The value of stabilization energy $\left(\mathrm{E}^{(2)}\right)$ indicated a stronger/stable bond. The NBO data showed that the most durable binding occurred at O61 $\cdots \mathrm{H} 48$ (Lp (2)O58 $\left.\rightarrow \mathrm{BD}^{*}(1) \mathrm{O} 11-\mathrm{H} 48,15.64 \mathrm{kcal} / \mathrm{mol}\right)$. The results of the NBO analysis supported the results obtained from the QTAIM analysis.

\section{Intrinsic Bond Strength Index (IBSI)}

IBSI analysis aims to characterize hydrogen bonds in cellulose-amylum complexes (Table 4). Based on the data obtained, the bonds of $\mathrm{O} 61 \cdots \mathrm{H} 48, \mathrm{O} 2 \cdots \mathrm{H} 95$, and O60 $\cdots \mathrm{H} 93$ had bond strength values IBSI ${ }^{\mathrm{IGM}}$ were 0.167 , 0.104 , and 0.116 , respectively. This value was in the hydrogen bonding range, $0.053-0.15$ [3]. The O61H48 bond value was the largest, indicating the strongest hydrogen bond in the cellulose-amylum complex. Simultaneously, the $\cdots \mathrm{H} 48$ bond distance $(\mathrm{r}=1.842 \AA)$ supported the shortest O61 statement. At the same time, the results of QTAIM and NBO are supported by IBSI analysis. Analysis results showed cellulose's potential in the manufacture of bioplastics (Table 4).

Based on the experimental data by Osman et al. (2020), the interaction of the amylum-cellulose complex increased and showed better film characteristics than amylum film [4]. In another study, Young's modulus of amylum film was increased by adding cellulose nanofiber (CNF) [34]. The computational results supported the experimental data about intermolecular interaction between amylum and cellulose. Moreover, these data proved the potential of cellulose as a support material with amylum in bioplastic's manufacture.

\section{- CONCLUSION}

This study evaluated the cellulose-amylum interaction using the DFT method's optimized molecular structure. The interaction energy in the complex is $-29.8 \mathrm{kcal} / \mathrm{mol}$, which indicates that the interaction formed is strong. The hydrogen bond at $\mathrm{O} 61 \cdots \mathrm{H} 48$ was the strongest in the cellulose-amylum complex.

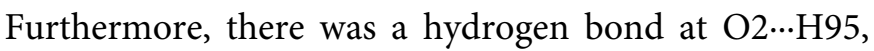
which was a little further away ( $\mathrm{r} \mathrm{OH}=1.999 \AA)$. The complex bond between cellulose and amylum results was lower than the cellulose in the HOMO-LUMO energy 
gap value, allowing the cellulose-amylum complex to interact. There were 15 critical BCP in the celluloseamylum complex, which indicated the presence of

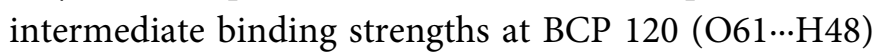
and $125(\mathrm{H} 95 \ldots \mathrm{O} 2)$. The critical BCP in the celluloseamylum complex could be related to the RDG and NCI index results. There was an increase in intermolecular bonds in the cellulose-amylum complex. The results of NBO also showed that the most stable binding occurred at $\mathrm{O} 61 \cdots \mathrm{H} 48\left(\mathrm{Lp}(2) \mathrm{O} 58 \rightarrow \mathrm{BD}^{*}(1) \mathrm{O} 11-\mathrm{H} 48,15.64\right.$ $\mathrm{kcal} / \mathrm{mol}$ ), which supported the results obtained from the QTAIM analysis. Both NBO and IBSI results were supported by the result of O61‥H48 bond analysis, which had the most considerable IBSI value of 0.167 . Overall calculation results showed that cellulose could interact with amylum. Therefore, cellulose could be a potential reinforcement in increasing amylum-based bioplastics' mechanical strength.

\section{- ACKNOWLEDGMENTS}

This research was funded by Directorate General of Higher Education (Direktorat Jendral Pendidikan Tinggi Kementrian Pendidikan, Kebudayaan, Riset dan Teknologi, SK 1949/E2/KM.05.01/2021) through Program Kreativitas Mahasiswa (PKM, student creativity program). This research was also supported by Atma Jaya Catholic University of Indonesia.

\section{- AUTHOR CONTRIBUTIONS}

Raynardthan Pontoh carried out writing, review, editing, and data curation in the manuscript. Vania Edita Rarisavitri advised methodology, and further manuscript write up improvement. Christine Charen Yang visualized the data and data curation in the manuscript. Maximillian Febriand Putra validated and investigated the manuscript. Daru Seto Bagus Anugrah carried out conceptualization, validation, investigation, methodology, resources, writing, editing, and the supervision. All authors read and approved the final version of the manuscript.

\section{- REFERENCES}

[1] Sahin, H.T., and Arslan, M.B., 2008, A study on physical and chemical properties of cellulose paper immersed in various solvent mixtures, Int. J. Mol. Sci.,
$9(1), 78-88$.

[2] Anugrah, D.S.B., Alexander, H., Pramitasari, R., Hudiyanti, D., and Sagita, C.P., 2020, A review of polysaccharide-zinc oxide nanocomposites as safe coating for fruits preservation, Coatings, 10 (10), 988.

[3] Bauer, C.A., Schneider, G., and Göller, A.H., 2019, Machine learning models for hydrogen bond donor and acceptor strengths using large and diverse training data generated by first-principles interaction free energies, J. Cheminf., 11 (1), 59.

[4] Osman, A.F., Ashafee, A.M.T.L., Adnan, S.A., and Alakrach, A., 2020, Influence of hybrid cellulose/bentonite fillers on structure, ambient, and low temperature tensile properties of thermoplastic starch composites, Polym. Eng. Sci., 60 (4), 810-822.

[5] Ketema, A., and Worku, A., 2020, Review on intermolecular forces between dyes used for polyester dyeing and polyester fiber, J. Chem., 2020, 6628404.

[6] Cai, W., Xiao, C., Qian, L., and Cui, S., 2019, Detecting van der Waals forces between a single polymer repeating unit and a solid surface in high vacuum, Nano Res., 12 (1), 57-61.

[7] Dong, M., Miao, K., Hu, Y., Wu, J., Li, J., Pang, P., Miao, X., and Deng, W., 2017, Cooperating dipoledipole and van der Waals interactions driven 2D self-assembly of fluorenone derivatives: Ester chain length effect, Phys. Chem. Chem. Phys., 19 (46), 31113-31120.

[8] Santana, R.F., Bonomo, R.C.F., Gandolfi, O.R.R., Rodrigues, L.B., Santos, L.S., dos Santos Pires, A.C., de Oliveira, C.P., da Costa Ilhéu Fontan, R., and Veloso, C.M., 2018, Characterization of starch-based bioplastics from jackfruit seed plasticized with glycerol, J. Food Sci. Technol., 55 (1), 278-286.

[9] Hudiyanti, D., Hamidi, N.I., Anugrah, D.S.B., Salimah, S.N.M., and Siahaan, P., 2019, Encapsulation of vitamin $\mathrm{C}$ in sesame liposomes: computational and experimental studies, Open Chem., 17 (1), 537-543.

[10] Agustin, M.B., Ahmmad, B., Alonzo, S.M.M., and Patriana, F.M., 2014, Bioplastic based on starch and cellulose nanocrystals from rice straw, J. Reinf. Plast. Compos., 33 (24), 2205-2213. 
[11] Rahmawati, S., Radiman, C.L., and Martoprawiro, M.A., 2018, Density functional theory (DFT) and natural bond orbital (NBO) analysis of intermolecular hydrogen bond interaction in "Phosphorylated nata de coco - water", Indones. J. Chem., 18 (1), 173-178.

[12] Costa, M.P.M., Prates, L.M., Baptista, L., Cruz, M.T.M., and Ferreira, I.L.M., 2018, Interaction of polyelectrolyte complex between sodium alginate and chitosan dimers with a single glyphosate molecule: A DFT and NBO study, Carbohydr. Polym., 198, 51-60.

[13] Hammami, F., Ghalla, H., and Nasr, S., 2015, Intermolecular hydrogen bonds in urea-water complexes: DFT, NBO, and AIM analysis, Comput. Theor. Chem., 1070, 40-47.

[14] Deka, B.C., and Bhattacharyya, P.K., 2017, DFT study on host-guest interaction in chitosan-amino acid complexes, Comput. Theor. Chem., 1110, 40-49.

[15] Cortes, E., Márquez, E., Mora, J.R., Puello, E., Rangel, N., De Moya, A., and Trilleras, J., 2019, Theoretical study of the adsorption process of antimalarial drugs into acrylamide-base hydrogel model using DFT methods: The first approach to the rational design of a controlled drug delivery system, Processes, 7 (7), 396.

[16] Uto, T., and Yui, T., 2018, DFT optimization of isolated molecular chain sheet models constituting native cellulose crystal structures, ACS Omega, 3 (7), 8050-8058.

[17] Junxi, L., Qiong, S., Yamin, Z., and Yanbin, W., 2016, Theoretical insights into three types of oxidized starch-based adhesives: Chemical stability, water resistance, and shearing viscosity from a molecular viewpoint, J. Chem., 2016, 2369739.

[18] Goerigk, L., 2014, How do DFT-DCP, DFT-NL, and DFT-D3 compare for the description of Londondispersion effects in conformers and general thermochemistry?, J. Chem. Theory Comput., 10 (3), 968-980.

[19] Grimme, S., Antony, J., Ehrlich, S., and Krieg, H., 2010, A consistent and accurate ab initio parametrization of density functional dispersion correction (DFT-D) for the 94 elements $\mathrm{H}-\mathrm{Pu}, J$. Chem. Phys., 132, 154104.
[20] Valiev, M., Bylaska, E.J., Govind, N., Kowalski, K., Straatsma, T.P., Van Dam, H.J.J., Wang, D., Nieplocha, J., Apra, E., Windus, T.L., and de Jong, W.A., 2010, NWChem: A comprehensive and scalable open-source solution for large scale molecular simulations, Comput. Phys. Commun., 181 (9), 1477-1489.

[21] Anugrah, D.S.B., Darmalim, L.V., Putro, P.A., Nuratikah, L.D., Sasongko, N.A., Siahaan, P., and Yulandi, A., 2021, Computational evaluation of intermolecular interaction in poly(styrene-maleic acid)-water complexes using density functional theory, Indones. J. Chem., 21 (6) 1537-1549.

[22] Lu, T., and Chen, F., 2012, Multiwfn: A multifunctional wavefunction analyzer, J. Comput. Chem., 33 (5), 580-592.

[23] Hidayat, Y., Armunanto, R., and Pranowo, H.D., 2018, QMCF-MD simulation and NBO analysis of $\mathrm{K}(\mathrm{I})$ ion in liquid ammonia, Indones. J. Chem., 18 (2), 203-210.

[24] Martins, J.B.L., Quintino, R.P., Politi, J.R.S., Sethio, D., Gargano, R., and Kraka, E., 2020, Computational analysis of vibrational frequencies and rovibrational spectroscopic constants of hydrogen sulfide dimer using MP2 and CCSD(T), Spectrochim. Acta, Part A, $239,118540$.

[25] Garces, V., García-Quintero, A., Lerma, T.A., Palencia, M., Combatt, E.M., and Arrieta, Á.A., 2021, Characterization of cassava starch and its structural changes resulting of thermal stress by functionally-enhanced derivative spectroscopy (FEDS), Polysaccharides, 2 (4), 866-877.

[26] Siahaan, P., Sasongko, N.A., Lusiana, R.A., Prasasty, V.D., and Martoprawiro, M.A., 2021, The validation of molecular interaction among dimer chitosan with urea and creatinine using density functional theory: In application for hemodyalisis membrane, Int. J. Biol. Macromol., 168, 339-349.

[27] Miar, M., Shiroudi, A., Pourshamsian, K., Oliaey, A.R., and Hatamjafari, F., 2021, Theoretical investigations on the HOMO-LUMO gap and global reactivity descriptor studies, natural bond orbital, and nucleus-independent chemical shifts 
analyses of 3-phenylbenzo[d]thiazole-2(3H)-imine and its para-substituted derivatives: Solvent and subs, J. Chem. Res., 45 (1-2), 147-158.

[28] Shabani, M., Ghiasi, R., Zare, K., and Fazaeli, R., 2020, Quantum chemical study of interaction between titanocene dichloride anticancer drug and $\mathrm{Al}_{12} \mathrm{~N}_{12}$ nano-cluster, Russ. J. Inorg. Chem., 65 (11), 1726-1734.

[29] Ghiasi, R., Emami, R., and Vasfi Sofiyani, M., 2021, Interaction between carboplatin with $\mathrm{B}_{12} \mathrm{P}_{12}$ and $\mathrm{Al}_{12} \mathrm{P}_{12}$ nano-clusters: A computational investigation, Phosphorus, Sulfur Silicon Relat. Elem., 196 (8), 751-759.

[30] Klein, J., Khartabil, H., Boisson, J.C., ContrerasGarciá, J., Piquemal, J.P., and Hénon, E., 2020, New way for probing bond strength, J. Phys. Chem. A, 124 (9), 1850-1860.

[31] Lefebvre, C., Khartabil, H., Boisson, J.C., ContrerasGarcía, J., Piquemal, J.P., and Hénon, E., 2018, The independent gradient model: A new approach for probing strong and weak interactions in molecules from wave function calculations, ChemPhysChem, 19 (6), 724-735.

[32] Jabłoński, M., 2020, A critical overview of current theoretical methods of estimating the energy of intramolecular interactions, Molecules, 25 (23), 5512.

[33] Rodrigues-Oliveira, A.F., Ribeiro, F.W.M., Cervi, G., and Correra, T.C., 2018, Evaluation of common theoretical methods for predicting infrared multiphotonic dissociation vibrational spectra of intramolecular hydrogen-bonded ions, ACS Omega, 3 (8), 9075-9085.

[34] Granda, L.A., Oliver-Ortega, H., Fabra, M.J., Tarrés, Q., Pèlach, M.À., Lagarón, J.M., and Méndez, J.A., 2020, Improved process to obtain nanofibrillated cellulose (CNF) reinforced starch films with upgraded mechanical properties and barrier character, Polymers, 12 (5), 1071. 